\title{
Phytochemical and In-vitro antioxidant activity of polyherbal formulation of medicinal plants
}

\author{
Dr. Dhana Rangesh Kumar $\mathrm{V}^{1^{*}}$, M. Sharu latha ${ }^{2}$ and Benitta Soosan Thomas ${ }^{2}$ \\ 1-Assistant Professor, 2-UG Students, PG and Research Department of Biochemistry, \\ Dr.N.G.P.Arts and Science College, Coimbatore, Tamil Nadu, India.
}

\begin{abstract}
:
Herbal plants produce a diverse range of bioactive molecules, making them rich source of different types of medicines. Thus, a proper scientific evidence or assessment has become the criteria for acceptance of herbal health claims. Plants based antioxidants are now preferred to synthetic ones because of safety concerns. There is an increasing interest in natural antioxidants e.g. Polyphenols, present in medicinal and dietary plants, which might help prevent oxidative damage. Natural antioxidant increases the antioxidant capacity of plasma and reduces the risk of disease. As such developing a polyhedral formulation will definitely produce synergistic effect as needed comparable to standard drugs that are available in market all over the world. The polyherbal formulation, which has a combination of medicinal herbs such as Zingiber officinale (sukku), Nigella sativa (karunjeeragam), Plectrantus amboinicus (karpooravalli), Pipeer cubeba (vaal melagu), Trigonella foenum graecum (venthayam) powder was tested for it's an antioxidant activity phenolic and alkaloid contents in vitro. The purpose of the present study was to investigate the In-vitro antioxidant phenolic and alkaloid content of polyherbal formulation and its application for treating life threatening disease such as cancer, cardiac disease, and diabetes mellitus. In this paper we report the result of such studies in order to orient future investigations towards the finding of new, potent safe and easily available food antioxidants.
\end{abstract}

KEYWORDS:Antioxidants, polyherbal formulation, medicinal herbs, phenolic. 


\section{Introduction}

The current trends for surviving long and healthy life entirely dependent on The traditional medication systems in which Ayurveda is one of the most favorable systems because of it possess several natural elements to eliminate the critical causes of the disease by restoring the equilibrium and preventing further reoccurrence [1]. WHO estimated that around $80 \%$ of the world's populations still trusting in traditional or Ayurvedic medicines for their healthy survival of life [2]. The Indian philosophy behind Ayurveda is to prevent unnecessary suffering of survival when curing the human ailments and also well-known for the significant biodiversity centers through concerning 45,000 herbal plant species out of which about 15,000 medicinal plants have been recorded to curing different human ailments by using single or multiple herbs for the complete elimination of disease [3].

The combination of various herbs (polyherbal) in a particular ratio will give a desirable therapeutic effect because the potent phytochemical constituents of individual plants are inadequate to achieve the beneficial effect $[4,5]$. The polyherbal formulation contains two ormore herbs with different phytoconstituents possessing similar or dissimilar therapeutic potential have been collectively producing desirable effects during the management of human ailments $[6,7]$. The popularity of the polyherbal formulation is outstanding because of their wide therapeutic range i.e., effective at a low dose and safe at high dose, though produces fewer side effects whilst misused [8, 9].

The various parts used in the Ayurvedic medicine are the seed, root, bark, stem, gum, leaves, flowers, fruit, etc. of the plants $[10,11]$. The purpose of present study was to investigate the antioxidant properties, phenolic and alkaloids contents of a polyherbal formulation, which has a combination of medicinal herbs such as Zingiber officinale (sukku), Nigella sativa (karunjeeragam), Plectrantus amboinicus (karpooravalli), Pipeer cubeba (vaal melagu), Trigonella foenum graecum (venthayam).The result of such studies in order to orient future investigations towards the finding of new, potent and safe antioxidant foodstuffs.

\section{Materials and methods}

\subsection{Collection of plant materials}

The Zingiber officinale (sukku), Nigella sativa (karunjeeragam), Plectrantus amboinicus (karpooravalli), Pipeer cubeba (vaal melagu), Trigonella foenum graecum 
(venthayam)were collected from super market, coimbatore. The specimens were identified by a taxonomist, Botanical Survey of India, Coimbatore.

\subsection{Processing of poly-herbal formulation}

The seeds and roots were shade dried for 4-6 weeks and powdered finely in a mixture and sieved twice to obtain a fine powder. $100 \mathrm{gm}$ of dried powder of each - Zingiber officinale (sukku), Nigella sativa (karunjeeragam), Plectrantus amboinicus (karpooravalli), Pipeer cubeba (vaal melagu), Trigonella foenum graecum (venthayam) were separately extracted with Soxhlet extractor using $100 \%$ ethanol till solvent was colourless. The extract was dried till constant weight was obtained. The yield was $21.16 \%$ for Zingiber officinale, $17.38 \%$ for Nigella sativa, $15.90 \%$ for Plectrantus amboinicus. $25 \mathrm{mg}$ of each extract was mixed together and henceforth labeled as Poly-herbal formulation. This mixture of $25 \mathrm{mg}$ each of residue was dissolved in $10 \mathrm{ml}$ of ethanol, boiled in water bath for 5 minutes, cooled and centrifuged at $4000 \mathrm{rpm}$ for 10 minutes. The clear supernatant was used for evaluating antioxidant properties in various assays.

\subsection{Phytochemical analysis:}

\subsubsection{Qualitative Phytochemical Analysis}

The herbal preparation was subjected to preliminary phytochemical studies using standard procedures to detect the phytochemicals present [12]. The polyherbal formulation was found to contain the important phytochemicals like Alkaloids, Flavanoids, Phenols etc., which proved to enhance the anti-oxidant potential

2.4 In Vitro Antioxidant Activities Different concentrations (50-250 $\mu \mathrm{g} / \mathrm{ml})$ of PHF were tested for various types of radicals scavenging potential.

\subsubsection{Free Radical Scavenging Activity on DPPH}

The antioxidant activity of the sample was determined in terms of hydrogen donating or radical scavenging ability, using the stable radical DPPH, according to the method of Blois (1958)

[13].

\subsubsection{Superoxide Radical Scavenging Activity}

Superoxide radicals were generated by a modified method of Beauchamp and Fridovich (1971) [14].

\subsubsection{Nitric Oxide Radical Scavenging Activity}

The nitric oxide scavenging activity of the sample was measured according to the method of Sreejayan and Rao (1997) [15]. 


\subsubsection{Ferric reducing antioxidant power (FRAP)}

The FRAP assay was used to estimate the reducing capacity of the sample, according to the method of Benzie and Strain (1996) [16].

\section{Results}

The medicinal plants, which contain the high amount of polyphenols, are considered to be good source of natural antioxidant compounds and more often possess higher antioxidant potential than that of dietary fruits and vegetables. Consumption of these plant products certainly prevents the free radical mediated damage in the cell and therefore protects the body from several health problems. These antioxidant compounds can be used as natural antioxidant additives or nutritional supplements in the food products. As of natural origin, these antioxidants are much safe to use. Thus, much attention has been focused on the investigation of natural antioxidant compounds from plants, which can effectively scavenge ROS [17].

\subsection{Qualitative analysis of PHF}

The preliminary phytochemical screening for ethanol extract of Pipe migrum, Trigonella foenum-graecum, Zingiber officinale, Nigella sativa, Plectranthus amboinicus was performed. Extraction and phytochemical screening was done using 100\% ethanol as the solvent. Phytochemical screening confirmed the presence of various phytoconstituents like alkaloids, phenols, carbohydrates, etc., and it is shown in table 1.

Table 1: Qualitative analysis of ethanolic extract of PHF

\begin{tabular}{|c|c|}
\hline TEST & OBSERVATION \\
\hline Alkaloids & + \\
\hline Saponin & - \\
\hline Glycosides & - \\
\hline Tannins & + \\
\hline Phenols & - \\
\hline Protein & + \\
\hline
\end{tabular}




\subsection{Antioxidant activity}

\section{DPPH Radical scavenging activity:}

The assay is based on the measurement of the scavenging ability of antioxidants. Fig. 1 showed the DPPH scavenging effect increased with the increasing concentration of polyherbal formulationas $\mathrm{IC}_{50}$ value of the polyherbal formulation was observed as $116.55 \mu \mathrm{g} / \mathrm{ml}$. In minimum concentration 50 the percentage of activity is $28.74 \pm 1.07$. In maximum concentration of 250 the percentage of activity is $69.82 \pm 1.12$. This shows the scavenging effect.

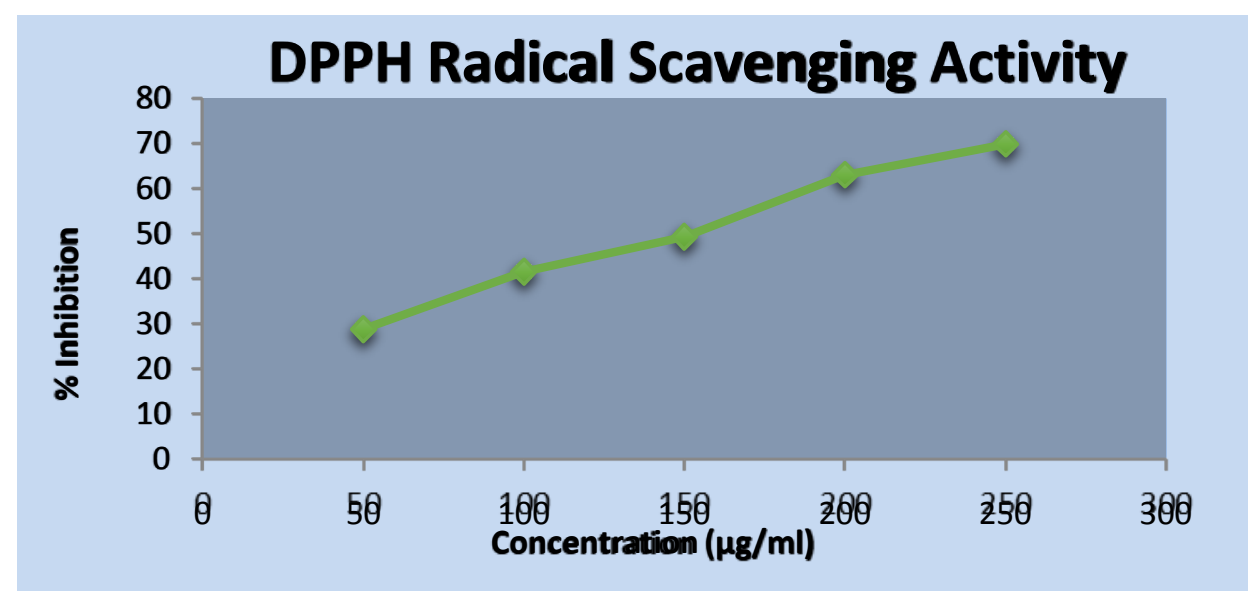

Fig.1: DPPH radical scavenging activity of ethanolic extract of PHF

Values are mean of three independent analysis \pm SD of triplicates $(n=3)$

\section{Nitric oxide radical scavenging activity:}

Nitric oxide is a free radical generated by endothelial cells, macrophages, neurons etc., and involved in the regulation of various physiological processes. The Nitric oxide radical scavenging activity increased with the increasing concentration of polyherbal formulation and $\mathrm{IC}_{50}$ value of the polyherbal formulation was observed as $160.90 \mu \mathrm{g} / \mathrm{ml}$. In minimum concentration 50 the percentage of activity is $25.37 \pm 1.63$. In maximum concentration of 250 the percentage of activity is $75.76 \pm 1.09$. This shows the scavenging effect are debited in the fig. 2 . 


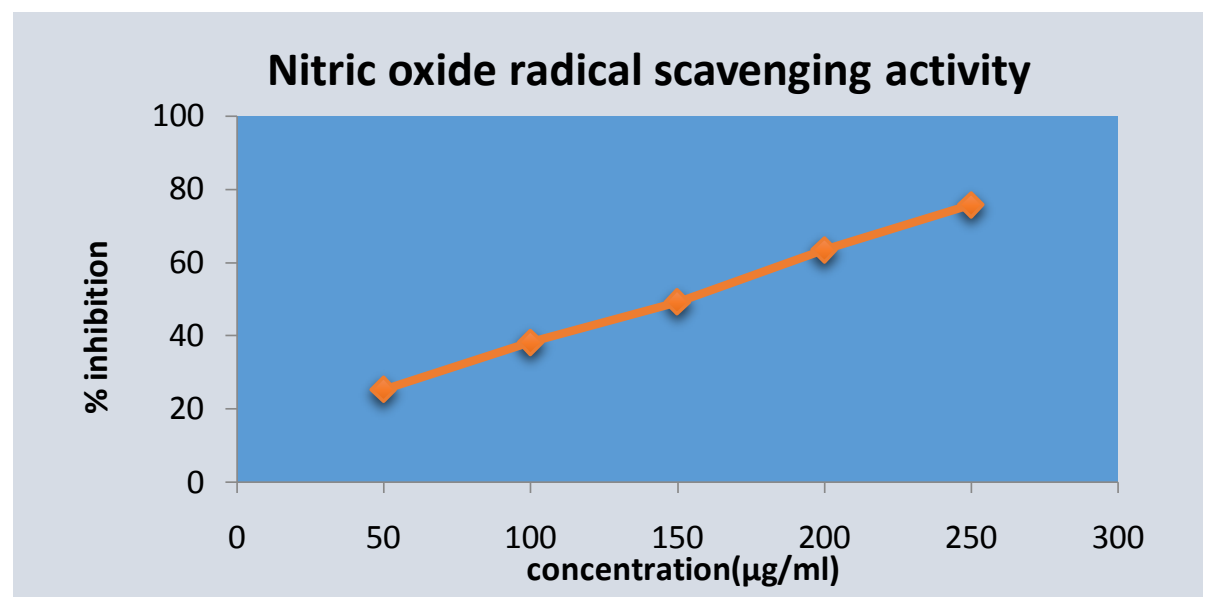

Fig. 2: Nitric oxide radical scavenging activity of ethanolic extract of PHF

Values are mean of three independent analysis \pm SD of triplicates $(n=3)$

\section{Super oxide scavenging activity:}

Superoxide's are produced from molecular oxygen due to oxidative enzymes of the body as well as by non-enzymatic reactions such as auto oxidation by catecholamine's. The Super oxidescavenging activity increased with the increasing concentration of polyherbal formulation and $\mathrm{IC}_{50}$ value of the polyherbal formulation was observed as $113.64 \mu \mathrm{g} / \mathrm{ml}$. In minimum concentration 50 the percentage of activity is $12.01 \pm 0.22$. In maximum concentration of 250 the percentage of activity is $30.26 \pm 0.47$. This shows the scavenging effect (Fig.3).

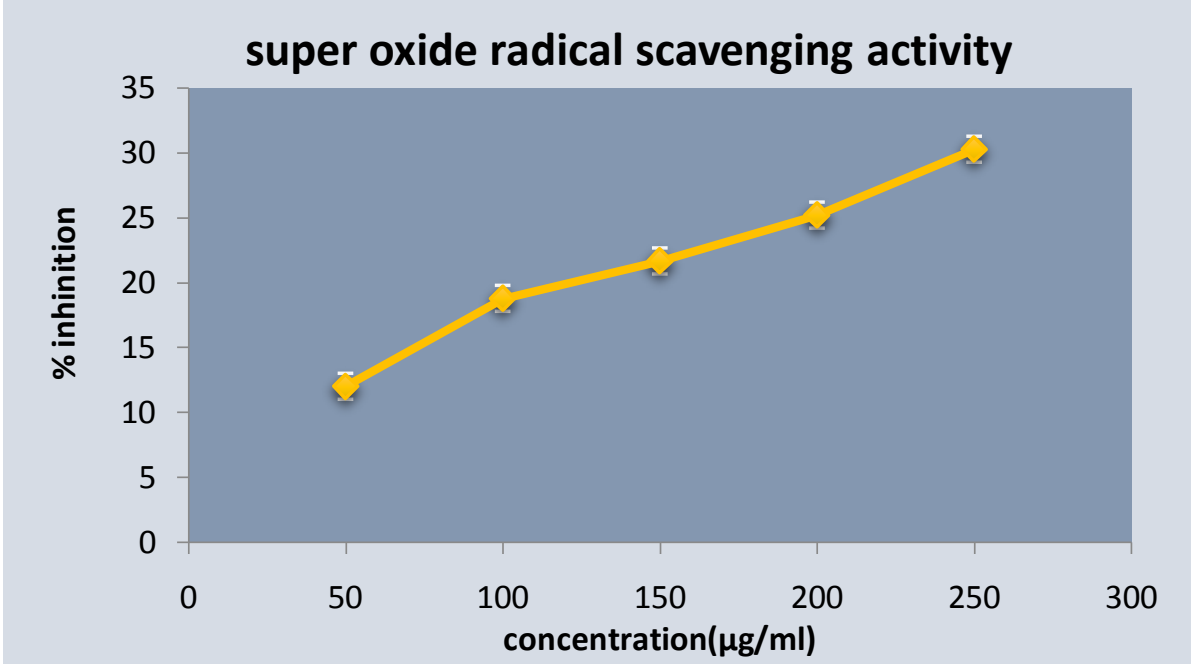

Fig. 3: Super oxide radical scavenging activity of ethanolic extract of PHF Values are mean of three independent analysis \pm SD of triplicates $(n=3)$ 


\section{Ferric reducing antioxidant power:}

The $100 \%$ ethanolic extract of polyherbal formulation had a strong ferric reducing antioxidant power of $160 \mu \mathrm{g} / \mathrm{ml}$. The ferric reducing antioxidant power increased with the increasing concentration of polyherbal formulation and $\mathrm{IC}_{50}$ value of the polyherbal formulation was observed as $160 \mu \mathrm{g} / \mathrm{ml}$. In minimum concentration 50 the percentage of activity is $17.36 \pm 1.12$. In maximum concentration of 250 the percentage of activity is 65.72 \pm 1.52 . This shows the scavenging effect (Fig.4).

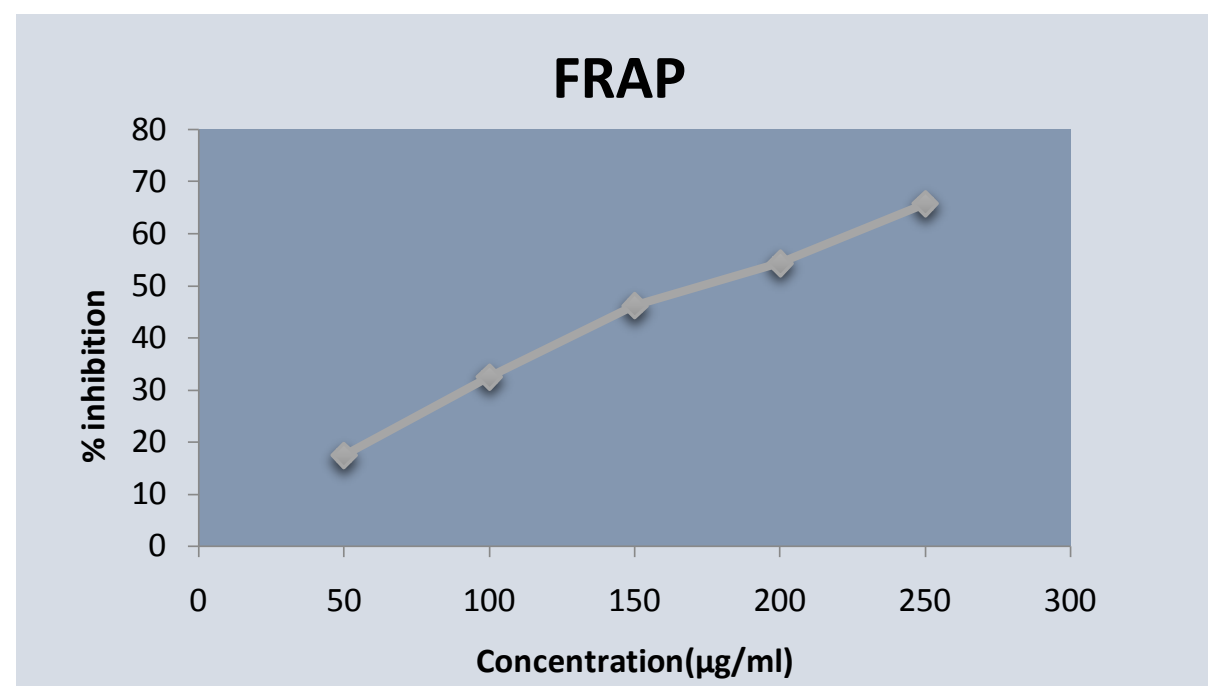

Fig. 3: Ferric reducing antioxidant powerAssay of ethanolic extract of PHF

Values are mean of three independent analysis \pm SD of triplicates $(n=3)$

\section{Discussion}

Free radicals are known to play a definite role in a wide variety of pathological manifestations. Their broad range effects in biological systems have drawn the attention of many experimental works. It has been proven that these mechanisms may be important in the pathogenesis of certain diseases and aging. There are many reports that support the use of antioxidant supplementation in reducing the level of oxidative stress and in slowing or preventing the development of complications associated with diseases. They exert their action either by scavenging the reactive oxygen speciesor protecting the antioxidant defense mechanisms [18].

The ethanolic extract of PHF contained appreciable amount of phenolics, alkaloids and carbohydrates. The presence of phenolics compounds may exert antioxidant effects and free radical scavengers, as hydrogen donating sources or as singlet oxygen quenchers and metal ion chelators[19](Hossain et al., 2012). 
DPPH is a relatively stable radical. The assay is based on the measurement of the scavenging ability of antioxidants towards the stable radical DPPH which reacts with suitable reducing agent. The electrons become paired off and the solution loses color stoichiometrically depending on the number of electrons taken up [20]. Showed the DPPH scavenging effect increased with the increasing concentrations of polyherbal formulation.

Nitric oxide is a free radical generated by endothelial cells, macrophages, neurons etc., and involved in the regulation of various physiological process [21]. The polyherbal formulation had a strong superoxide radical scavenging activity.

Superoxides are produced from molecular oxygen due to oxidative enzymes of the body as well as by non-enzymatic reactions such as auto-oxidation by catecholamines [13]. The polyherbal formulation had a strong superoxide radical scavenging activity.

\section{Conclusion}

The results of the present study showed that the ethanolic extract of polyherbal formulation contains alkaloids, carbhohydrates and phenols which exhibited greater anti-oxidant activity. The high scavenging activity of the polyherbal formulation may be due to hydroxyl groups existing in the phenolic compounds, chemical structure that can provide the necessary component as radical scavenger. Free radicals are often generated as byproducts of biological reactions or from environmental factors. So the study shows that ethanolic extract of polyherbal formulation shows good anti-oxidant and free radical scavenging activity. A potent scavenger of free radicals may serve as a possible preventative intervention for the diseases like cancer,diabetes mellitus, we have included Nigella sativa (karun jeeragam) which have 100\% hydroxychloroquine which helps to improve immunity against corona virus. The outcome of the project is to be medicine or a food recipe.

\section{Acknowledgement}

The authors wish to acknowledge the use of instrumentation and infrastructure facilities provided by DST-FIST and DBTStar college scheme, Ministry of Science and Technology, Govt. of India for the successful completion of project dissertation. We thank to the host institution Dr.N.G.P. Arts and Science College, Management, Principal, Deans, Head of the Department, Guide, and all other staffs of Department of 
Biochemistry for rendering all the facilities and support. Communication number: DrNGPASC 2020-21 BS072.

\section{Conflict of Interest}

The authors declare no conflict of interest

\section{References}

1. Hankey A. Ayurveda and the battle against chronic disease: an opportunity for ayurveda to go mainstream. J Ayurveda Integ Med 2010; 1:9-12.

2. Chaudhary A, Singh N. Contribution of world health organization in the global acceptance of ayurveda. J Ayurveda Integ Med 2011; 2:179-86.

3. Parasuraman S, Thing GS, Dhanaraj SA. Polyherbal formulation: concept of ayurveda. Pharmacogn Rev 2014; 8:73-80.

4. Pandey MM, Rastogi S, Rawat AKS. Indian traditional ayurvedic system of medicine and nutritional supplementation. J Evidence Based Complementary Altern Med 2013:1-12. http://dx.doi.org/10.1155/2013/376327

5. Garg V, Dhar VJ, Sharma A, Dutt R. Facts about standardization of herbal medicine: a review. Zhong Xi Yi Jie He Xue Bao 2012; 10:1077-83.

6. Awasthi H, Mani D, Nath R, Nischal A, Usman K, Khattri S. Standardization, preparation and evaluation of an Ayurvedic polyherbal formulation in a capsule dosage form suitable for use in clinical trials. Indo Am J Pharm Res 2014; 4:4093-9.

7. Mathew L, Babu S. Phytotherapy in India: the transition of tradition to technology. Curr Bot 2011; 2:17-22.

8. Srivastava S, Lal VK, Pant KK. Polyherbal formulations based on Indian medicinal plants as antidiabetic phytotherapeutics. Phytopharmacology 2012; 2:1-15.

9. Kapoor VK, Singla S. Herb-drug interactions-an update on synergistic interactions. J Alt Med Res 2015; 1:1-11.

10. Gurley BJ. Pharmacokinetic herb-drug interactions (Part 1): Origins, mechanisms, and the impact of botanical dietary supplements. Planta Med 2012; 78:1478-89.

11. Rawat R, Vashistha DP. Common herbal plant in Uttarakhand, used in the popular medicinal preparation in ayurveda. Int J Pharmacogn Phytochem Res 2011; 3:64-73.

12. Harborne JB, Trease GE: Phytochemical methods: A guide to modern technique of plant 
analysis, 3rd edn. Chapman and Hall, London,pp 114-118, 1978.

13. Blois MS:Antioxidant determinations by the use of a stable free radical. Nature 1958, 26:1199-1200

14. Beauchamp C, Fridovich I: Superoxide dismutase: improved assays and an assay applicable to acrylamide gels. Analytical Biochemistry 1971, 44:276-277

15.Sreejayan $\mathrm{N}$ and Rao MNA: Nitric oxide scavenging by cucuminoids. Journal of Pharmacy and Pharmacology1971, 49:105-107

16. Benzie IFF and Strain JJ: The ferric reducing ability of plasma (FRAP) as a measure of “Antioxidant power” The FRAP assay. Analytical Biochemistry 1996; 239: 70-76

17. Aruoma OI: Methodological considerations for characterizing potential antioxidant actions of bioactive components in plant foods. Mutation Research 2003; 523 (524):9-20.

18. Umamaheswari, M., Chatterjee, T.K. (2008). In vitro antioxidant activities of the fractions of Coccinia Grandis L. leaf extract. Afr J Trad Comp Alter Med. 5: 61-73. 19.Hossain, M.A., Shah, M.D., Gnanaraj, C., Iqbal, M., 2011. In vitro total phenolics, flavonoids contents and antioxidant activity of essential oil, various organic extracts from the leaves of tropical medicinal plant Tetrastigma from Sabah. Asian Pacific J. Trop. Med. 4 (9), $717-721$.

20. Gaurav Kumar, Loganathan Karthik and Kokati Vankata Bhaskara Rao: Phytochemical composition and in-vitro antioxidant activity of aqueous extract of Aerva lanata (L.) stem (Amaranthaceae). Asian Pacific Journal of Tropical Medicine 2013; 180-187.

21. Braugghler J M, Duncan C A and Chase L R: The involvement of iron in lipid peroxidation. Importance of ferrous to ferric iron in initation. Journal biological chemistry 1986; 261:10282-9. 